\title{
ENTREVISTA NUMA ABORDAGEM COMPREENSIVA - RELATO DE UM EXERCÍCIO PRÁTICO
}

\author{
Margarita Villar Luis * \\ Maria Conceiçào Bernardo Mello e Souza ** \\ Renata Curi Labate***
}

LUIS, M. V. et al. Entrevista numa abordagem compreensiva: relato de um exercício prático. Rev. Esc. Enf. USP., v. 27, n.3, p. 372-86, dez.1993.

$O$ estudo aborda a entrevista, numa perspectiva centrada na pessoa e propōe a reflexão sobre esse tema extremamente importante, devendo ser incluído no ensino de graduação em Enfermagem, devido à dificuldade do aluno em abordar e conduzir uma entrevista. Em relação a isso, as autoras apresentam os resultados de um exercício prático que evidencia a tendência de respostas dos alunos na condução da entrevista.

UNITERMOS: Entrevistas, Estudante de enfermagem.

No decorrer de anos ministrando disciplinas na área de Enfermagem Psiquiátrica, detectamos as dificuldades que o aluno tem em abordar adequadamente os pacientes em geral e em conduzir uma conversação com os mesmos. Esse fato pode ser estendido tanto a paciente portador de um distúrbio psiquiátrico, quanto àquele portador de um problema orgânico não enquadrado na clínica psiquiátrica, mas que apresenta alteraçōes emocionais as quais podem ter uma solução ou encaminhamento, desde que haja um profissional de saúde que demonstre disponibilidade para ouvir com atenção.

Pensando na formação do enfermeiro, no lidar com "gente", e considerando que essa é uma característica bastante específica desse profissional, ressaltamos a importância de constar em seu currículo o tema "Entrevista de ajuda". Através desse conteúdo, podemos oferecer aos alunos a oportunidade de refletir sobre o "encontro" entre duas pessoas, onde o objetivo do entrevistador é ajudar o entrevistado.

Enfermeira. Professor Doutor da Escola de Enfermagem de Ribeirão Preto - USP, Departamento de Enfermagem Psiquiátrica e Cièncias Humanas.

- Enfermeira. Auxiliar de Ensino da Escola de Enfermagem de Ribeirảo Preto - USP, Departamento de Enfermagem Psiquiátrica e Ciências Humanas.

*** Enfermeira. Assistente da Escola de Enfermagem de Ribeirāo Preto - USP, Departamento de Enfermagem Psiquiátrica e Cièncias Humanas. 
Tal posicionamento é decorrente da concepção que temos a respeito da entrevista, pois, no nosso entender, trata-se de um momento em que ocorre uma inter-relação humana com uma finalidade específica, que pode conduzir a uma evolução pessoal. Isso porque possibilita o compartilhar de vivências, onde o entrevistador escuta e facilita o entendimento da situação ao entrevistado e este, por sua vez, dá a oportunidade ao entrevistador de conhecer mais sobre o ser humano e sobre si mesmo, o que contribui para sua experiência profissional e de vida.

Visando a reflexão sobre esse "encontro", docentes da disciplina de Introdução à Saúde Mental*, vêm oferecendo há três anos no seu programa, a aula sobre entrevista de ajuda. Com a experiência acumulada nesse período, percebemos que se trata de um assunto para ser abordado de maneira sistematizada e com mais profundidade junto ao aluno, uma vez que no decorrer dos quatro anos de graduação ele trabalha prioritariamente com pessoas.

\section{FUNDAMENTAÇÃO TEÓRICA}

HULAK (1988) parece compartilhar de nossas preocupações, no que se refere à introdução da técnica da entrevista nos currículos oficiais da formação de profissionais da área de saúde. $O$ autor afirma que a entrevista é a "primeira ferramenta de trabalho" desses profissionais que lidam com pessoas, pois é não só o primeiro passo para o diagnóstico como, na maior parte das vezes, o único instrumento terapêutico e o próprio caminho da cura.

Contudo, o primeiro problema com que nos deparamos foi a escolha da fundamentação teórica para embasar os conteúdos a serem ministrados aos alunos, pois trata-se de literatura muito vasta e diversificada. Com isso, decidimos pela escolha de alguns autores com os quais nos identificávamos mais, a fím de poder elaborar um corpo teórico que se adequasse aos nossos propósitos.

\section{Definindo a entrevista}

Segundo Smith; Bass (1982) citados por HULAK (1988), a entrevista é o intercâmbio de comunicações verbais e não verbais entre duas ou mais pessoas, com a intenção expressa de trocar informações e dados pertinentes ao tema em questão.

Disciplina que consta do currículo do Curso de Graduação da Escola de Enfermagem de Ribeirāo Preto- USP., oferecida no $4^{\circ}$ semestre letivo. 
Para HULAK (1988), a entrevista é uma forma de tratamento de problemas através da qual, uma pessoa especialmente treinada e uma pessoa em busca de ajuda se encontram em um ambiente especialmente preparado, onde o terapeuta estabelece, intencionalmente, um relacionamento profissional, que vise à compreensão de problemas do paciente e o planejamento da busca de soluçōes.

BENJAMIN (1978), entende a entrevista como um encontro entre duas pessoas, onde o objetivo do entrevistador é ajudar o entrevistado. Essa ajuda pode acontecer ou não e para que ela ocorra, é condição necessária, a existência de um relacionamento caracterizado pela confiança mútua, e o incentivo à mudança criativa.

MUCHIELLI (1979), refere-se especificamente à entrevista de aju$\mathrm{da}$, entendendo-a como uma entrevista face-a-face, sendo essa configuração o meio de se operar a relação de ajuda.

$O$ autor citado, define a relação de ajuda como uma relação profíssional, onde "uma pessoa deve ser assistida para operar seu ajustamento pessoal a uma situação à qual ela não se adaptava normalmente". Para tanto, pressupõe que o "ajudador" seja capaz de... "compreender o problema nos termos em que se coloca para tal indivíduo singular, em sua existência singular", e de ajudá-lo "a evoluir pessoalmente no sentido de melhor adaptação social".

Entretanto, é importante se ter em mente, que essa meta não é alcançada com facilidade. É o que se depreende da referência de BENJAMIN (1978), quando o mes mo faz consideraçoes sobre "ajuda", que segundo seu entendimento, é "um ato de capacitação, ou seja, o entrevistador capacita o entrevistado a reconhecer, sentir, saber, decidir e escolher se deve mudar".

Para esse autor, o ato de capacitação exige que o entrevistador doe parte de si mesmo e, se essa doação puder ser sentida pelo entrevistado, o ato de capacitação encontrará receptividade, isto é, o entrevistado receberá ajuda de maneira adequada e significativa para ele.

Com isso, BENJAMIN (1978) entende a entrevista de ajuda como uma ampla interação verbal entre entrevistador e entrevistado na qual se dá o ato de capacitação. Contudo, mesmo que isso venha a ocorrer, não é sempre que os objetivos são alcançados (a mudança, a adaptação), pois muitas vezes, não é possível constatar se eles foram ou não atingidos.

Dessa exposição teórica, verificamos que a entrevista de ajuda constitui-se num intercâmbio de comunicação verbal e não verbal entre duas pessoas, predominantemente no face-a-face. Pressupondo que uma pessoa busca ajuda e a outra esteja capacitada e disponível para ajudar, a entrevista de ajuda consiste num encontro, cujo objetivo é ajudar através de um relacionamento profissional (que visa a compreensāo) caracterizado pela confiança mútua e pela ocorrência de mudanças - soluçōes que podem ser adaptaçōes ou criaçōes novas. 
O papel fundamental do indivíduo que ajuda, não é o de trazer uma solução pronta para aquela situação que é problema para o entrevistado, mas sim o de revigorar e utilizar os recursos disponíveis pelo próprio indivíduo. Portanto, o entrevistador deve facilitar a expressão do outro, iniciando por desenvolver a sua própria capacidade de escuta e observação (MUCHIELLI, 1979).

Assim sendo, com um vínculo sedimentado pela confiança e segurança, se estabelece uma relação dialética em que o entrevistador somente pode compreender se o entrevistado se expressar e este, por sua vez, se compreende reforçando sua própria reflexão propiciada pelo entrevistador (MUCHIELLI, 1979, BENJAMIN, 1978).

Esse processo ocorre da seguinte maneira: quando o entrevistado faz suas colocações e o entrevistador escuta, é como dizer-lhe: "Estou ouvindo você" ou "Então é assim que você vê a coisa?". Com isso, indicamos a ele o que nos mostrou, para que possa examiná-lo, tomar consciência e "pensar sobre". O que nós, na condição de entrevistadores, devolvemos ao entrevistado são fatos que ele falou, os quais podem parecer "bons" ou "maus", "certos" ou "errados", segundo nossa avaliação. Contudo, a despeito desses julgamentos de valor, os relatamos conforme os recebemos do entrevistado.

Tal postura, requer que a pessoa a qual se propõe a ajudar, conheça suficientemente o seu contexto pessoal, a fim de poder avaliar as distorções introduzidas pelas suas opiniōes, crenças, preconceitos e estereótipos, naquilo que ouve e observa do entrevistado no decorrer da entrevista (MUCHIELLI, 1979).

A conduta de tornar a dizer, em outras palavras (de modo mais conciso ou explícito), aquilo que o entrevistado acaba de expressar, e de maneira que ele concorde com os termos em que foi exprimido, caracteriza uma intervenção do entrevistador, denominada por MUCHIELLI (1979) de "reformulação", e que, segundo seu entender, é a técnica de base da entrevista de ajuda.

Para o autor, com isso obtém-se de imediato três primeiros resultados: (1) o entrevistador certifica-se de que não introduziu nada de diferente ou interpretativo na comunicação escutada; (2) o entrevistado, ao reconhecer-se na reformulaçāo, certifica-se que está no caminho certo para se fazer compreender, sentindo-se estimulado a dar continuidade à expressão; (3) o entrevis tador comprova que escutou e compreendeu o que lhe foi dito pelo entrevistado.

Portanto, a entrevista de ajuda não é uma conversação no sentido de "travar conhecimento" com a pessoa, embora em suas fases iniciais isso possa ocorrer. Ela também não é discussão de opositores numa relação de dominação - submissão, nem um interrogatório com um "bombardeio" de perguntas. Tampouco se trata de um discurso, um monólogo de uma das partes, ou uma confissão em que um indivíduo julga o 
comportamento do outro, ou a busca de enquadrá-la num determinado quadro clínico. A "boa entrevista" segundo MUCHIELLI (1979), tem como objetivo "a compreensão exata daquilo que se passa com o outro, a descoberta do modo pelo qual ele sente a situação, a clarificação progressiva de sua vivência".

Assim, procurando transportar esses conhecimentos para a nossa prática de ensino, o objetivo desse estudo foi investigar qual a tendência natural do aluno, na condução de uma entrevista de ajuda, através de um exercício prático realizado na sala de aula.

\section{METODOLOGIA}

1. População: Fizeram parte do estudo: 49 alunos do $4^{2}$ ano de graduação de 1989, 32 alunos de 1990 , e 49 alunos do $2^{2}$ ano de graduação* de 1991, num total de 130 alunos.

2. Instrumento: Utilizou-se um exercício de interação proposto por MUCHIELLI (1979), a partir de dez fragmentos de entrevistas (de pessoas diferentes) gravados em fita cassete e apresentados aos alunos de cada um dos anos referidos, na própria classe. Esse exercício era oferecido após a aula em que ministramos o conteúdo teórico de entrevista.

O exercício segundo o autor, visa a descoberta das atitudes espontâneas dos participantes e consta de duas partes: a exploração individual e a exploração em grupo. $O$ estudo em questão abordou apenas a segunda parte, a qual se propõe a descobrir no grupo, a variedade e subjetividade das respostas, bem como a atitude dominante em termos de tendência de abordagem do paciente.

Os fragmentos de entrevistas são denominados de "casos" e enumerados de 1 a 10. Para cada um deles há a oferta de 6 respostas possíveis, cada uma com significação diversa, indicando a tendência do indivíduo no tocante à condução da entrevista durante uma abordagem de paciente, como exemplo segue-se o fragmento de entrevista que corresponde ao caso $\mathrm{n}^{2} 10$ :

Professor, eu queria que o senhor me ajudasse sobre meu programa para o próximo trimestre. Falei com diversas pessoas sobre o que eu devo escolher, mas cada uma me diz coisas diferentes e está bem dificil para eu saber o que devo fazer. $O$ senhor sabe, estou só no primeiro ano, e não sei realmente o que vale mais a pena.

- Alternativas para a resposta.

Is8o ocorreu devido à mudança da disciplina para o $4^{\circ}$ semestre, em funçảo do curriculo ter sido alterado na EERP.USP. O $n^{\circ}$ total de alunos frequentando essa disciplina no $4^{\circ}$ ano de 1989 e 1990 , foi respectivamente 50 e 36 . No $2^{p}$ ano de 1991 , esse total foi de 71 . 
1. Se eu compreendi bem, você considera que se trata de alguma coisa que precisa de uma ajuda exterior, alguma coisa que você náo pode decidir por si mesmo.

2. Você quer ralar da seç̧ão para o qual você quer entrar e do que você vai escolher como matéria optativa?

3. Olhe, se você levar em conta um pouco mais a si mesmo, quanto ao que você pode fazer e quer fazer, em lugar de dar tanta importância ao que dizem os outros... talvez você assim se sentisse um pouco melhor.

4. Aí eu me pergunto se a solução para suas dificuldades não estaria num desenvolvimento maior de sua auto-confiança mais do que fazer escolhas entre os cursos.

5. Certamente, vamos refletir sobre o problema. Às vezes é um pouco difícil encontrar seu lugar na estrutura do colégio.

6. Você já fez o balanço das matérias que terá de cursar e o balanço das horas de trabalho de que você poderá dispor?

$\mathrm{Na}$ "correção" do exercício é apresentado um esquema (quadro 1) de 10 colunas correspondentes cada uma a um caso e 6 linhas horizontais. Essas linhas são identificadas pelas letras do alfabeto e indicam a categoria representativa de uma determinada tendência, conforme pode ser observado na descrição de cada uma delas:

A. Avaliação ou julgamento mora;

B. Interpretação por deformaçāo do pensamento do outro ou por tentativa de explicação;

C. Apoio afetivo, encorajamento, simpatia consoladora;

D. Investigação, questionamento, busca de informaçōes complementares;

E. Solução do problema;

F. Compreensão tipo reformulação, refletindo o mais exatamente possivel aquilo que o outro quis dizer.

O cruzamento das colunas com as linhas forma 60 caselas, que no gabarito fornecido pelo autor do exercício, estão preenchidas com números, cada qual correspondendo a uma resposta, como pode ser constatado no seguinte quadro: 


\begin{tabular}{|l|c|c|c|c|c|c|c|c|c|c|}
\hline & Quso 1 & Caso 2 & Caso 3 & Caso 4 & Caso 5 & Caso 6 & Caso 7 & Caso 8 & Caso 9 & $\begin{array}{c}\text { Caso } \\
10\end{array}$ \\
\hline A & 2 & 1 & 5 & 6 & 6 & 2 & 5 & 3 & 4 & 3 \\
\hline B & 4 & 2 & 1 & 5 & 2 & 6 & 1 & 4 & 2 & 2 \\
\hline C & 6 & 5 & 6 & 1 & 5 & 4 & 3 & 6 & 1 & 5 \\
\hline D & 1 & 4 & 3 & 3 & 1 & 5 & 6 & 1 & 5 & 6 \\
\hline E & 3 & 6 & 4 & 2 & 4 & 1 & 2 & 5 & 6 & 4 \\
\hline F & 5 & 3 & 2 & 4 & 3 & 3 & 4 & 2 & 3 & 1 \\
\hline
\end{tabular}

No Quadro I, as respostas aos casos estão dispostas de tal forma que todas aquelas inseridas numa mesma horizontal, correspondem a aquelas reveladoras de uma mesma tendência de resposta durante a abordagem do paciente. Por exemplo, na linha F, estão dispostas todas as respostas indicadoras de atitude compreensiva (dadas aos 10 casos)

\section{Procedimento}

Foram distribuídas individualmente aos alunos, folhas contendo todas as alternativas de respostas correspondentes a cada caso, com a orientação de que iriam ouvir dez fragmentos de entrevistas, feitas com dez pessoas diferentes, e que a cada um deles correspondiam seis respostas possíveis. A tarefa dos alunos consistia em assinalar aquela resposta, que se aproximasse mais da que eles dariam espontaneamente à uma pessoa que lhes tivesse feito essa confidência e esperasse uma resposta.

Em seguida, a gravação dos fragmentos de entrevista dos dez casos, foi apresentada, caso a caso, um após o outro (em geral repetindo-se cada um ao menos duas vezes), com intervalos que possibilitassem ao aluno assinalar sua resposta.

Uma vez apresentados todos os casos (fragmentos de entrevistas), procedia-se à "correção". Para tanto, apresentava-se aos alunos o quadro gabarito e ao lado deste um quadro similar não preenchido. A seguir, perguntava-se à classe as respostas dadas a cada fragmento de entrevista. Por ex., "para o fragmento 1, quem respondeu a resposta número 1 , levantem a mão?" Supondo que 5 pessoas se pronunciassem, anotava-se esse número no quadro não preenchido, na coluna "caso $1^{1 "}, 4^{\mathrm{a}}$ linha (já que no gabarito a resposta $n^{2} 1$ situava-se nessa linha). Esse procedimento era repetido, com todas as respostas dos dez casos. Assim, obtínhamos ao final, o número total de alunos que haviam assinalado cada resposta de cada um dos casos.

Destacamos que nesse momento os participantes não possuíam a significação de suas respostas e assim sendo, não conheciam o sentido 
das seis categorias definidas anteriormente, o qual somente era apresentado ao término da "correçāo" do exercício.

\section{RESULTADOS: ANÁLISE E DISCUSSĀO}

De posse do resultado do exercício, verificando as respostas dos alunos individualmente, o mesmo possibilitou que fosse detectada uma certa linha dominante, ou seja, aquela que horizontalmente apresentou o maior número de caselas preenchidas (cinco ou mais). Pudemos observar ainda, a presença de linha subdominante (aparecendo junto com a dominante) e outra(s) de casos isolados, que são respostas que estão sozinhas ou em número inferior a três nas linhas horizontais.

A presença de uma linha dominante, segundo MUCHIELLI (1979) indica a tendência habitual ou crônica do entrevistador diante de uma pessoa numa situação de entrevista ou de confidências recebidas. Através do exercício, o aluno pode perceber sua atitude corriqueira manifestada através de suas respostas aos fragmentos de entrevistas.

Pode haver ainda, segundo esse autor, a existência de sub-dominante, revelando uma outra tendência habitual do entrevistador, na situação com um entrevistado.

As respostas isoladas (casos isolados) nas linhas horizontais, isto é, quando não há dominante nem sub-dominante, indicam que a resposta do entrevistador é induzida pelo tipo de situação vivenciada por ele ou pelo personagem que lhe é apresentado. Portanto, trata-se de um indivíduo que se deixa levar pelas suas emoçōes e que se mostra facilmente impressionável, predominando a sugestibilidade na sua interaçāo com o outro. (MUCHIELLI, 1979).

No que se refere à população estudada neste trabalho, observamos algumas diferenças nos resultados obtidos, as quais serão detalhadas à seguir.

\section{Freqüência de linhas dominantes e de casos isolados}

No $4^{\circ}$ ano de graduação de 1989 , verificamos que o grupo apresentou linhas dominantes e sub-dominantes. A dominante mais freqüente, para um grupo de 18 alunos, foi aquela com respostas em número de 6 a 10 (sem sub-dominante). A segunda linha dominante para 12 alunos apresentou-se com 5 respostas numa mesma horizontal (acompanhada de 1 sub-dominante e casos isolados). A terceira ocorrência de dominante com 3 respostas apareceu em 10 alunos; nessa configuração, como o número de respostas por dominante foi pequeno, ocorreu o aparecimento simultâneo, de outra dominante (com o mesmo $n^{2}$ de respostas) ou de casos isolados. Por fim, a quarta possibilidade em termos de dominantes, (com 
1 sub-dominante) ocorreu para 9 alunos, que assinalaram 4 respostas numa mesma linha.

A síntese desses resultados encontra-se no quadro a seguir:

Quadro II - Regumo dos Regultados do ano de 1989. freqüència do $n^{\circ}$ de respostas em cada dominante, assinalada pelos alunos.

\begin{tabular}{|c|c|c|}
\hline Linha & N $^{2}$ de Respostas & $N^{2}$ de Alunos \\
\hline Dominante & $6 \cdot 10$ & 18 \\
\hline $\begin{array}{c}\text { Dominante } \\
\text { (1 sub-dominante) } \\
\text { (casos isolados) }\end{array}$ & 5 & 12 \\
\hline $\begin{array}{c}\text { Dominante } \\
\text { (2 cdominantes") } \\
\text { (casos isolados) }\end{array}$ & 4 & 9 \\
\hline $\begin{array}{c}\text { Dominante } \\
\text { (1 sub-dominante) }\end{array}$ & 3 & 10 \\
\hline Total & & 49 \\
\hline
\end{tabular}

No $4^{2}$ ano de 1990 , observamos algumas características que definiram o grupo estudado com uma configuração diferente da apresentada pelo primeiro. Esses alunos, também apresentaram linhas dominantes em termos de respostas: a mais freqüente com 13 alunos, foi a de 5 respostas (com 1 sub-dominante); a segunda dominante mais comum para 8 alunos, foi a de 6 a 9 respostas (acrescidas da presença de casos isolados) na mesma linha horizontal. A terceira dominante, para 7 alunos, foi a de 4 respostas (com presença de 1 sub-dominante); por último, evidenciamos 2 alunos com dominante de 3 respostas e 2 alunos, cujas respostas se constituíram exclusivamente de casos isolados.

O quadro III sumariza as explicações anteriores.

\begin{tabular}{|c|c|c|}
\hline \multicolumn{3}{|c|}{$\begin{array}{l}\text { Quadro III - Resumo dos Resultados do ano de } 1890 \text { : freqüència do } n^{\circ} \text { de respostas em cads } \\
\text { dominante, aseinalados pelos alunos. }\end{array}$} \\
\hline Linha & $\mathrm{N}^{2}$ de Respostas & $\mathrm{N}^{2}$ de Alunos \\
\hline $\begin{array}{c}\text { Dominante } \\
\text { (1 sub-dominante) }\end{array}$ & 5 & 13 \\
\hline $\begin{array}{l}\text { Dominante } \\
\text { (casos isolados) }\end{array}$ & 6 a 9 & 8 \\
\hline $\begin{array}{l}\text { Dominante } \\
\text { (1 sub-dominante) }\end{array}$ & 4 & 7 \\
\hline $\begin{array}{l}\text { Dominante } \\
\text { (casos isolados) }\end{array}$ & 3 & 2 \\
\hline Casos isolados & & 2 \\
\hline Total & & 32 \\
\hline
\end{tabular}


O último grupo de alunos da nossa população, correspondeu àqueles de 1991 , do $2^{\circ}$ ano de graduaçāo, os quais apresentaram características peculiares no que se refere ao resultado da aplicaçāo do exercício.

Foi evidenciada uma linha "dominante" mais freqüente, representada por 23 alunos, com apenas três respostas numa linha horizontal (mais a presença de casos isolados); a segunda dominante mais freqüente nesse grupo, para 14 alunos, apresentava 4 respostas; a última dominante com 5 alunos, incluía 5 respostas (com presença de casos isolados) na mesma horizontal. Finalmente 4 alunos apresentaram menos de 3 respostas na mesma horizontal. te.

Essas explicaçōes podem ser melhor visualizadas, no quadro seguin-

\begin{tabular}{|c|c|c|}
\hline \multicolumn{2}{|c|}{ Quadro IV-Resumo dos Resultados do ano de 1991 } \\
\hline $\begin{array}{c}\text { Linha } \\
\text { (2 dominante } \\
\text { (casos isolados) }\end{array}$ & No de Respostas & No de Alunos $^{\circ}$ \\
\hline $\begin{array}{c}\text { Dominante } \\
\text { (1 sub-dominante) } \\
\text { (casos isolados) }\end{array}$ & 4 & 23 \\
\hline Dominante & 5 & 5 \\
\hline Dominante & $6 \cdot 7$ & 3 \\
\hline Caso isolado & & 4 \\
\hline Total & & 49 \\
\hline
\end{tabular}

Observando as características de cada um desses grupos realizados $(1989,1990,1991)$ notamos que há entre eles configurações diversas. A diferença a que nos referimos diz respeito ao número de respostas existentes nas linhas dominantes mais freqüentes de cada um dos grupos. Pareceu-nos que do grupo de 1989 até o de 1991, elas foram diminuindo, conforme pode ser evidenciado pelos Quadros II, III e IV, correspondentes. Por ex., a dominante mais freqüente do grupo de 1989 apresentou 18 alunos com número de seis a dez

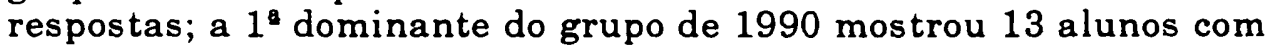

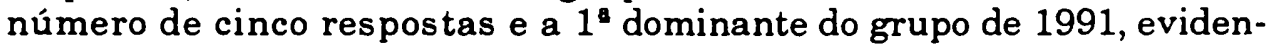
ciou 23 alunos com três respostas.

MUCHIELLI (1979) mencionando a significação das dominantes, relata que uma dominante com nove respostas sobre dez (casos) denota uma atitude rígida ou sistemática, ao passo que quatro sobre dez revela uma tendência.

Observando os resultados obtidos em termos de dominantes, com a população estudada, notamos que no ano de 1989 houve uma parcela maior (18 alunos) em que é possível, se considerar a ocorrência de uma 
atitude mais sistemática, no que se refere a comportamento durante a entrevista. Em 1990, observamos essa mesma atitude num grupo de oito alunos e em 1991, constatamos, apenas 3 alunos com essa mesma característica na resposta.

No que se refere à tendência de resposta, segundo especificado pelo autor citado, percebemos que é possível verificá-la numa parcela significativa de representantes dos anos de 1989 e 1990, conforme indicado pela segunda e quarta dominantes desse primeiro ano (com 21 alunos). Consideramos portanto que quatro e cinco respostas numa mesma linha horizontal, são indicativas de que o aluno revela mais uma tendência do que uma atitude rígida direcionando a entrevista.

Consideramos que essas peculiaridades sejam decorrentes do fato de que se trata de alunos pertencentes ao $4^{2}$ ano de graduação. Nas discussões realizadas em classe, percebemos nos seus relatos, que de alguma forma eles se sentiram induzidos, no decorrer dos anos de graduação anteriores a se conduzir de determinada maneira. Isso parece ter contribuído para um comportamento durante a entrevista, que culminou na freqüência maior de algumas dominantes específicas, as quais serão abordadas posteriormente quando nos referimos aos dados da população total.

Observando o ano de 1991, notamos diferenças acentuadas com os grupos dos anos anteriores, pois o que predominou foi um grupo de 23 alunos, que se enquadrariam no que MUCHIELLI (1979) denomina de casos sem resposta dominante, tratando-se de respostas isoladas. Em seguida, constatamos a presença de uma parcela de 19 alunos que indicariam uma tendência de resposta.

Essas diferenças nos resultados, sugerem haver uma relação com o fato dessa amostra ser constituída de alunos do $2^{\circ}$ ano, portanto em início de formação, apesar de estarem incluídos nesse grupo, também elementos que já exercem atividades de enfermagem em instituições (técnicos, auxiliares e atendentes).

Assim sendo, pensamos que parte dos alunos representantes desse ano, embora indique (conforme o autor mencionado denomina) uma conduta de sugestibilidade durante a entrevista, seja mais receptiva ao aprendizado e treinamento em técnica de entrevista devido a sua inexperiência no lidar com pessoas. No que se refere a elementos do grupo que já atua na profissão de enfermagem, pensamos que talvez haja maior resistência a mudanças de atitudes, uma vez que vem reproduzindo essa maneira de se conduzir com clientes ao longo dos anos. Trata-se entretanto, de uma pressuposição que deve ser submetida a estudos posteriores a fim de ser confirmada.

$\mathrm{Na}$ seqüência, o Quadro $\mathrm{V}$ sumariza esse conteúdo exposto, no intuito de fornecer uma visão total dos resultados. 


\begin{tabular}{|c|c|c|c|c|c|}
\hline \multicolumn{6}{|c|}{$\begin{array}{l}\text { Quadro V · Caracterizaçào das atitudes da populaçào estudada, segundo o número de respostas } \\
\text { por dominante. }\end{array}$} \\
\hline $\begin{array}{l}\text { Ano } \\
\mathrm{N}^{2} \text { de } \\
\text { Resp./dominante }\end{array}$ & 1989 & 1990 & 1991 & Significaçāo & Total $\%$ \\
\hline 06 a 10 & 18 & - & - & $\begin{array}{l}\text { Atitude Rígida ou } \\
\text { Sistemática }\end{array}$ & $2922 \%$ \\
\hline 06 a 09 & - & 8 & - & & \\
\hline 06 a 07 & - & - & 3 & & \\
\hline 04 e 05 & 21 & 20 & 19 & Tendência de resposta & $6046 \%$ \\
\hline 03 & 10 & 2 & 23 & Sugestibilidade & $4132 \%$ \\
\hline Outros & - & 2 & 04 & & \\
\hline Total & 49 & 32 & 49 & & 130100 \\
\hline
\end{tabular}

Em termos de significação observamos nesse quadro, que 22\% (29 alunos) da populaçāo estudada apresentou uma atitude mais para rígida ou sistemática em suas respostas aos fragmentos de entrevista; $46 \%$ (60 alunos), revelou ter apenas tendência habitual nas respostas e por último, $32 \%$ (41 alunos), indicaram ser alvo de sugestibilidade ao darem as respostas.

\section{Atitudes habituais mais freqüentes na população estudada}

Sabendo que cada linha horizontal, representada por uma letra de $A$ até $\mathrm{F}$, incluía as diversas opçōes de respostas aos fragmentos de entrevista e relembrando que cada uma dessas letras tinha um significado em termos de atitudes habituais no face-a-face, a tarefa final desse estudo, consistiu em expor a distribuição total das tendências de resposta, que mais se destacaram na população de 130 alunos, obtida através da somatória de respostas/categoria, de cada grupo estudado (1989, 1990, 1991), conforme revelado no quadro a seguir. 
Quadro VI - Distribuiçào das somatórias totais de respostas dadas pelos alunos por categoria (horizontais - A, B, C, D, E, F) conforme o ano $1889,1890,1891$.

\begin{tabular}{|l|c|c|c|c|c|c|}
\hline \multirow{2}{*}{ ANO } & \multicolumn{5}{|c|}{ SOMATÓRIA DE REPOSTAS/CATEGORIA DE CADA GRUPO } \\
\hline 1989 & D (191) & A (45) & E (32) & F (130) & C (35) & B (58) \\
1990 & D (149) & A (46) & E (45) & F (30) & C (28) & B (22) \\
1991 & D (140) & A (96) & E (93) & F (72) & C (48) & B (42) \\
\hline TOTAL & D (480) & A (187) & E (170) & F (232) & C (111) & B (122) \\
\hline
\end{tabular}

O Quadro VI evidencia que em 1989 em termos de respostas, a linha dominante foi a $\mathrm{D}$, seguida pela $\mathrm{F}$ e em $3^{2}$ lugar com diferença significativa aparece a B. Permanece no ano de 1990, a predominância na linha $\mathrm{D}$, seguida com grande distância pelas linhas $\mathrm{A}, \mathrm{E}$ e F, que apresentaram proximidade no que diz respeito a número de respostas. Em 1991, continuam sendo mais freqüentemente assinaladas as respostas que se incluem na linha $D$, relativamente próximas a esta, observam-se as linhas $\mathrm{A}$, e $\mathrm{E}$ ambas com praticamente o mesmo número de respostas. Nesse ano a $\mathrm{F}$ aparece em $4^{2}$ lugar, ainda com um número significativo de respostas (cerca da metade do número encontrado na $D$ ).

Numa visão geral do quadro, considerando-se o número total de respostas em cada categoria para todos os anos, observa-se que o número maior de respostas recaiu na horizontal $D$, seguido de longe pela $F, A$ e E nessa ordem, cujo número total de respostas é bastante próximo.

Quanto ao aspecto qualitativo desses resultados, relembramos que a linha D pressupōe atitude de investigaçāo, questionamento... e a linha F, compreensão tipo reformulação, ou seja, devolver para o outro o que ele quis dizer de forma mais clara. A categoria A, pressupöe respostas avaliativas ou julgamento moral e a categoria $\mathrm{E}$ é indicativa de respostas que tendem a uma solução imediata do problema.

Ao cruzar os resultados referentes às características da população estudada no que diz respeito a se tratar de atitudes rígidas, sistemáticas ou tendência de resposta, podemos inferir que esses alunos apresentam uma tendência de resposta nessas categorias especificadas, com uma predominância para as respostas investigadoras.

Essas informaçōes levantam alguns questionamentos relativos à forma de abordar o paciente, levando-nos a pensar sobre os fatores que podem estar interferindo para que os alunos tenham se aproximado do paciente com uma atitude de investigação e não de ajuda. Nos anos de 1990 e 1991, a situação encontrada nos parece ainda mais grave, uma vez que, a segunda categoria mais freqüente diz respeito à abordagem com atitude de avaliação ou julgamento moral. 
Os resultados evidenciam a necessidade de refletir sobre quem está sendo o modelo para os alunos, particularmente, nas atividades práticas, onde ele tem a oportunidade de lidar com o paciente.

Considerando que na maioria das vezes o modelo é o docente, como este profissional está se conduzindo durante a abordagem dos pacientes? Como está passando as orientaçōes aos alunos no tocante à forma de abordar o paciente?

Outra questão emergente, refere-se à concepção que os docentes têm sobre a entrevista: há entre todos uma uniformidade de pensamento, no sentido de perceber a entrevista como um momento de ajuda, mesmo em se tratando de situação de coleta de dados para planejamento assistencial, ou para investigaçōes científicas?

Essas questōes, no nosso entender, nāo serão respondidas a curto prazo, já que estão na dependência de discussōes mais amplas entre o corpo docente e de uma análise mais aprofundada de conteúdos das disciplinas.

Julgamos que a solução passe também, pelo entendimento de fato entre os envolvidos (docentes e discentes), de que o paciente não deve ser percebido como um ser passivo, moldável às nossas necessidades e aspirações

No tocante à entrevista, reportamo-nos à BENJAMIN (1978), onde ele a diferencia em dois tipos: "aquela na qual o entrevistador procura a ajuda do entrevistado, e aquela em que o entrevistador tenta ajudar o entrevistado". O autor alerta para o fato dos limites entre ambas nem sempre serem definidos claramente, embora o propósito de cada uma seja evidente, pois na entrevista de ajuda, o entrevistado é o centro e, tudo o mais é acidental.

Entendemos que a entrevista de ajuda é um instrumento essencial para o enfermeiro, mas ela só é viável quando se concebe o paciente na qualidade de ator: "um homem que possui uma tendência inerente a desenvolver todas as suas capacidades de maneira que sirvam a preservar ou enriquecer seu organismo - a pessoa total, mente e corpo". (ROGERS; ROSEMBERG, 1977).

Esse postulado básico, segundo nossa compreensāo deve permanecer presente em toda a situação inerente à Enfermagem seja qual for o objetivo (assistencial ou pesquisa) e à especialidade ministrada. Caso contrário, há o risco do aluno incorporar a idéia de que a abordagem do paciente se faz conforme a disciplina que estiver cursando.

\section{CONSIDERAÇŌES FINAIS}

Os dados obtidos neste trabalho nos parecem relevantes, pois trata-se de uma primeira tentativa de avaliar através da aplicação de um instrumento, as atitudes espontâneas ou não do aluno no decorrer da entrevista face-a-face com outra pessoa (cliente). Reconhecemos a 
existência de aspectos que provavelmente foram sub-avaliados, como o fato de os resultados terem emergido de um exercício apenas, por isso os consideramos como sendo preliminares, um alerta a ser comprovado com a aplicação sucessiva de estudos semelhantes. Contudo não podemos deixar de ressaltar, o aspecto significativo desse exercício, ao indicar a predominância da tendência das respostas dos alunos, para a abordagem investigadora na entrevista. Este fato nos leva a refletir sobre o como esses alunos estão abordando o cliente numa situação real de atendimento. Para as autoras, o trabalho proporcionou uma oportunidade de pensar a esse respeito e um incentivo em direção da busca de alternativas, que visem desenvolver habilidades para melhorar a qualidade da interação aluno-cliente; nesse sentido, julgamos válida a iniciativa do estudo.

LUIS, M.V. et al. A comprehensive approach to the interview - report of a practical exercise.

Rev. Esc. Enf. USP., v. 27, n.3, p. 372-86, dec. 1993.

The paper was studied the interview in a person-entered perspective. It suggests the reflection about this very important theme. It should be included in the nursing teaching due to the difficulty that the student has in conducting an interview. The authors also present, the results of a practical exercise which reveals the tendency of the students responses in conducting an interview.

UNITERMOS: Interview. Students nursing.

\section{REFERÊNCIAS BIBLIOGRÁFICAS}

BENJAMIN, A. A entrevista de ajuda. São Paulo, Martins Fontes, 1978.

HULAK, S. Entrevista, mitos, métodos e modelos. 2ed. Recife, OEDIP, 1988.

MUCHIELLI, R. A entrevista não diretiva. São Paulo, Martins Fontes, 1978.

ROGERS, C.R.; ROSEMBERG, R.L. A pessoa como centro. São Paulo, E.P.U.,1977. 